\title{
0094. Monocyte tace activity profile during sepsis and systemic inflammatory response syndrome
}

\author{
DJ O'Callaghan ${ }^{1,2}$, KP O'Dea $^{1 *}$, M Takata ${ }^{1}$, AC Gordon ${ }^{1,2}$ \\ From ESICM LIVES 2014 \\ Barcelona, Spain. 27 September - 1 October 2014
}

\section{Introduction}

To date, immune-modulatory treatments in sepsis have proved unsuccessful. Better understanding of inflammatory processes might help tailor such therapies more effectively and improve their efficacy. It is now recognised that some patients may require immune stimulating therapies.

Monocytes display altered behaviour in response to systemic inflammation; this has been called "deactivation" and is characterised by reduced HLA-DR expression and attenuated tumour necrosis factor- $\alpha$ (TNF) release in response to lipopolysaccharide (LPS) stimulus ${ }^{1}$. TNF converting enzyme (TACE), activated via p38-mitogen activated protein kinase (MAPK) mediated pathway ${ }^{2}$, is essential for the shedding of TNF and TNF receptors (TNFRs)-1\&2. Altered TACE behaviour may be mechanistically important in deactivation.

\section{Objectives}

To determine whether monocyte TACE activity is affected by sepsis and is reflective of illness severity.

\section{Methods}

Sixteen patients with sepsis, 15 healthy volunteers and 8 patients with non-infectious systemic inflammatory response syndrome (NI-SIRS) were recruited and data collected at baseline (D0), day 2 (D2) and day 4 (D4). Peripheral blood mononuclear cells were separated by density gradient centrifugation with HLA-DR, TACE and TNFR expression (basal and LPS-induced) determined by flow cytometry. LPS-induced TNF release was measured using ELISA. Monocytes were isolated using magnetic bead selection and TACE catalytic activity (basal and LPS-induced) was measured using fluorescence resonance energy transfer assay ${ }^{3}$.

${ }^{1}$ Imperial College London, London, UK

Full list of author information is available at the end of the article

\section{Results}

HLA-DR expression and LPS-induced monocyte TNF release were attenuated in sepsis and NI-SIRS $(\mathrm{p}<0.01)$, consistent with deactivation. Sepsis, but not NI-SIRS, produced elevated basal monocyte TACE activity ( $\mathrm{p}<$ 0.01 ) while LPS-induced increases in TACE activity were attenuated. Elevated D0 basal TACE activity positively correlated with APACHE II score in sepsis $(\mathrm{p}<0.01)$, but not NI-SIRS.

TACE expression was unaltered across all groups, but LPS-induced TNFR shedding appeared reduced by sepsis. Sepsis patients displayed an attenuated p38-MAPK response to LPS.

\section{Conclusions}

Our data indicate that sepsis induces specific changes in monocyte TACE catalytic activity profiles that may reflect illness severity, whilst such changes were not seen in NI-SIRS. These changes in TACE activity attenuated LPS-induced release of TNFR and TNF from monocytes, and appear to be mediated through altered upstream p38-MAPK signalling.

\section{Grant acknowledgment}

UK Intensive Care Foundation Young Investigator Award.

\section{Authors' details}

${ }^{1}$ Imperial College London, London, UK. ${ }^{2}$ Imperial College Healthcare National Health Service Trust, London, UK.

Published: 26 September 2014

\section{References}

1. Volk HD, Reinke P, Krausch D, Zuckermann H, Asadullah K, Müller JM, Döcke WD, Kox WJ: Monocyte deactivation-rationale for a new therapeutic strategy in sepsis. Intensive Care Med 1996, 22(Suppl 4):p. S474-p.S481.

2. Scott AJ, O'Dea KP, O'Callaghan D, Williams L, Dokpesi JO, Tatton L, Handy JM, Hogg PJ, Takata M: Reactive oxygen species and p38 mitogenactivated protein kinase mediate tumor necrosis factor a-converting

\section{SpringerOpen ${ }^{\odot}$}

(c) 2014 O'Callaghan et al; licensee Springer. This is an Open Access article distributed under the terms of the Creative Commons Attribution License (http://creativecommons.org/licenses/by/2.0), which permits unrestricted use, distribution, and reproduction in any medium, provided the original work is properly cited. 


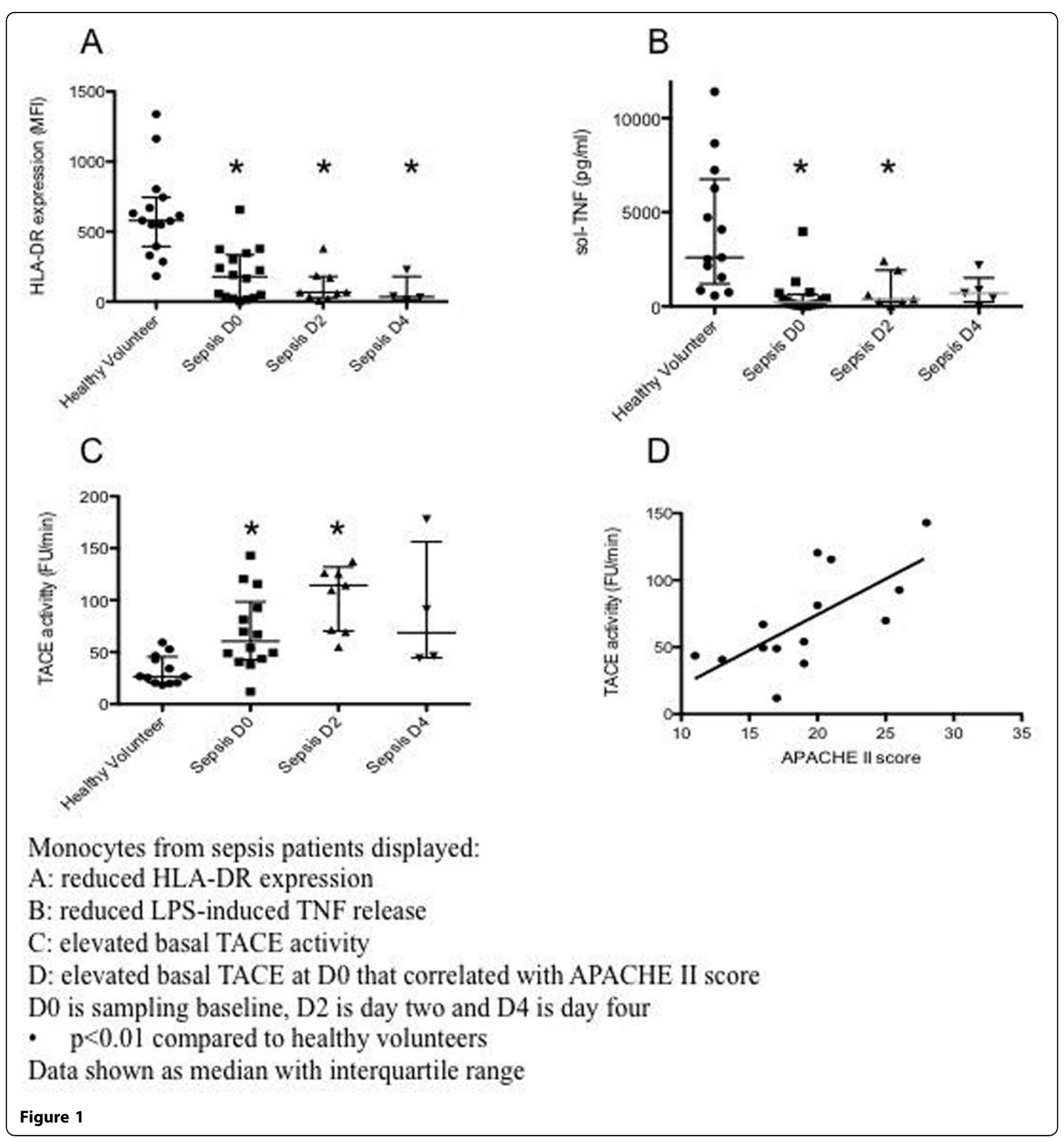

enzyme (TACE/ADAM-17) activation in primary human monocytes. $J$ Biol Chem. 2011, 286(41):35466-35476.

3. Alvarez-Iglesias A, Wayne G, O'Dea KP, Amour A, Takata M: Continuous real-time measurement of tumor necrosis factor-alpha converting enzyme activity on live cells. Lab Invest. 2005, 85(11):1440-1448. 